\title{
A leitura E SEUS LOCAIS; OS ESPAÇOS DE LEITURA No Brasil do SÉculo XIX NA ObRa de José DE Alencar
}

\author{
Reading and their locations; the reading spaces in the nineteenth \\ century Brazil in the work of José de Alencar
}

\section{La lectura y sus ubicaciones; los espacios de lectura en el siglo XIX Brasil en la obra de José de Alencar}

\author{
Daniela Casoni Moscato ${ }^{1}$ \\ Cláudio DeNipoti ${ }^{2}$
}

\begin{abstract}
Resumo: Este artigo busca explorar os métodos de pesquisa e a produção de conhecimento acerca do passado, baseados nas práticas em torno da palavra impressa, em especial aquelas relacionadas às formas de leitura. Neste sentido, foca-se na experiência de leitura do escritor brasileiro do século XIX, José Martiniano de Alencar, naquilo que diz respeito aos locais de leitura experimentados por ele e seus contemporâneos. O local destinado à leitura, em suas várias formas, expressa a organização cultural em torno da própria leitura e de formas de sociabilidade a ela associadas. Assim, salas familiares onde se faz uma leitura coletiva, ouvida por membros da família, bibliotecas e clubes de leitura devotados à leitura estudantil, ou mesmo locais imaginados como ideias, são buscados em fontes produzidas por José de Alencar, seja sua autobiografia, seja sua prosa ficcional, ou os elementos adicionais (paratextos) contidos nessa prosa.
\end{abstract}

Palavras-chave: José de Alencar. História da Leitura. História do Livro.

Abstract: This article explores the research and writing methods around the history of the printed word, particularly those related to forms of reading in the past. As such, it centers the analysis around the reading experiences of 19th Century Brazilian writer José Martiniano de Alencar and his contemporary countrymen. The place where reading happens expresses the cultural organization around reading itself and shows different related forms of sociability. So, family reading rooms where a collective reading takes place, libraries and reading clubs associated to student reading, or event imagined ideal reading places, are sought in sources Alencar himself has produced, like his autobiography, his fictional work, or the non-fictional elements (footnotes, for example) of his romances.

Keywords: José de Alencar. Reading History. Book History.

1 Universidade Federal do Paraná e Universidade de Coimbra.

2 Programa de Pós-Graduação em História UEPG.

\begin{tabular}{|lrllll|}
\hline TEL & IRATI (PR)/PontA GROSSA (PR) & V.6 N.1 & P. 13-27 & JAN./Jun. 2015 & E-ISSN: 2177-6644 \\
DOI 10.5935/2177-6644.20150002 & & & & \\
\hline
\end{tabular}


Resumen: En este estudio se trata de explorar los métodos de investigación y la producción de conocimiento con respecto al pasado y la base de prácticas en torno a la palabra impresa, especialmente, los aspectos relativos a las formas de lectura. Es centrado en la investigación de la experiencia vivida por el escritor brasileño del siglo XIX, José Martiniano de Alencar. Refierese a la lectura de locales experimentada por él y sus contemporáneos. El sitio para la lectura en sus diversas formas, expresa la organización cultural en torno a la propia lectura y formas de sociabilidad asociadas a él. Por lo tanto, se busca en la producción alencariana las habitaciones familiares donde se realiza una lectura colectiva para familiares, las bibliotecas de lectura y los clubes dedicados a la lectura por estudiantes, o incluso espacios imaginados como ideales para leer-se textos. Tal investigación comporta su autobiografía, su la prosa de ficción, incluso elementos adicionales (paratextos) presentes en su prosa.

Palabras clave: José de Alencar. Historia de la Lectura. Historia del Libro.

A história da palavra impressa é o campo de produção historiográfica que se preocupa com as formas de transmissão de conhecimento em torno de práticas de escrita e leitura, envolvendo aí o mundo do livro em sua produção e consumo. Neste sentido, envolve as tradições específicas da história da leitura, como praticada, principalmente, a partir da década de 1980, como forma de buscar a experiência cultural no passado (CHARTIER, 1995, 2004a; DARNTON, 1986). Resultante das mudanças epistemológicas do final do século XX, este campo do conhecimento histórico diz respeito à arte da narração, pela escolha de enredos e intrigas (VEYNE, 1983, p. 310), que oferecem uma história potencialmente dedicada a todo e qualquer acontecimento, inclusive às próprias concepções e formas de escrita da história no passado. Ao mesmo tempo, é pensado em termos de sua aproximação com a Antropologia e a Literatura. Essas inflexões acerca da História, por sua vez, fornecem a épistémê necessária para refletir sobre: 1) a hermenêutica, que observa nos dados culturais indícios ou sinais relativos a questões antropológicas de natureza mais profunda, acompanhando as obras e reflexões de Carlo Ginzburg; 2) campos de dispersão das práticas singulares, cuja proximidade somente pode ser entendida por meio da raridade ou singularidade do objeto, de acordo com o pensamento de Michel Foucault; e 3)
“[...] o papel da linguagem e das estruturas narrativas na criação e descrição da realidade histórica". (CARDOSO JR., 2001, p. 13-30). Hermenêutica, práticas e estruturas narrativas proporcionam os instrumentos necessários para compreender os indivíduos em suas interações sociais no passado. Essas características podem ser ilustradas pela vasta produção historiográfica dedicada à micro-história e à história cultural nas últimas décadas (BURKE, 2005), escritas com duas preocupações simultâneas: a de evitar a "distorção teleológica" e o obscurantismo, e a de ligar "eventos particulares a processos históricos mais amplos, [...] misturando narrativa e análise”. (CANNADINE, 1987, p. 170).

As investigações em torno da palavra impressa procuram compreender as práticas que, no passado, conformavam as múltiplas relações culturais em torno do livro e da leitura para buscar respostas às questões cruciais colocadas ao próprio campo. Por um lado, pensa-se a escrita:

Como podemos entender os modos como a forma que transmite um texto a seus leitores ou ouvintes conforma a produção de sentido? A apropriação do discurso não é algo que acontece sem regras ou limites. A escrita emprega estratégias que visam produzir efeitos, ditar posturas e prender o leitor. Ela prepara armadilhas nas quais o leitor cai sem mesmo perceber, pois as 
armadilhas são construídas de acordo com uma inventividade rebelde que ele ou ela presumivelmente possuem. Mas esta inventividade em si, depende em talentos específicos e hábitos culturais que caracterizam todos os leitores, na medida em que todos pertencem a comunidades de interpretação. Esta dialética de restrição imposta e invenção ocorre onde as convenções que hierarquizam gêneros, codificam formas e distinguem entre discurso que é literal ou figurativo, histórico ou fabuloso, demonstrativo ou persuasivo, encontram os esquemas de percepção e julgamento inerentes a cada comunidade de leitores (CHARTIER, 1995, p. 01).

Por outro, buscam-se estudar todas as etapas entre a escrita e o seu consumo pelos leitores, naquilo que Darnton descreve como um "[...] circuito de comunicação que corre do autor ao editor, ao impressor, ao despachante, ao livreiro e ao leitor [...]" (DARTON, 2002, p. 10-26), voltando, por vezes, ao autor por meio das reações dos leitores, das exigências dos diversos agentes do comércio do livro, ou das demandas da censura. Trata-se, portanto, de um campo cuja distinção advém da ênfase sobre a cultura impressa e o papel dos livros "[...] como objetos materiais dentro daquela cultura” (FINKELSTEIN; McCLEERY, 2002, p. 1), cabendo ao historiador reconstruir as variações que diferenciam o espaço legível, que Chartier caracteriza como "[...] os textos em suas formas materiais e discursivas" (CHARTIER, 2002, p. 48), daquelas variações que governam “[...] as leituras vistas como práticas concretas e procedimentos interpretativos". Não há, contudo, nenhuma dissociação concreta entre práticas e textos, dada a umbilicalidade de sua associação.

As reconstruções feitas dentro desta abordagem têm privilegiado (ainda que não tenham dado exclusividade) a estudos acerca das sociedades de Antigo Regime, entre os séculos XVI e XVIII, pois é nesse período que a palavra impressa tem penetração maior e mais marcada, com relação a outras formas de transmissão de conhecimento, nas sociedades ocidentais. Isto, por sua vez, nos permite compreender a importância dada, então, à escrita e aos seus suportes, por parte das autoridades que buscavam "regular os comportamentos e moldar as mentes" por meio do papel "pedagógico, aculturador e disciplinar atribuído aos textos em circulação para um corpo mais amplo de leitores", da vigilância exercida sobre a imprensa através da censura, que variava "da proibição brutal à interpretação autorizada, de disciplinas exteriores (administrativas, judiciais, inquisitoriais, acadêmicas, etc.,) aos mecanismos que, no próprio livro, buscam limitar a liberdade do leitor" (CHARTIER, 2002, p. 56).

A história do livro e da palavra impressa é, também, a história dos locais em que a leitura acontece, que pode ser a biblioteca particular, seja ela constituída em função de busca do conhecimento ou da ostentação social (DENIPOTI, 2009, p. 177-197), ou a biblioteca de acesso público, que congrega diferentes leitores e estabelece regras de conduta com relação à leitura e ao livro (DENIPOTI, 2007). Neste sentido, buscar os locais de leitura permite visualizar práticas relacionadas à própria leitura:

O 'onde' da leitura é mais importante do
que se poderia pensar, pois a colocação
do leitor em seu ambiente pode dar
sugestões sobre a natureza de sua
experiência (DARNTON, 1992, p. 213).

Este trabalho busca investigar as questões relacionadas aos locais de leitura em um recorte específico em torno da vida e da obra do romancista brasileiro José Martiniano de Alencar - um leitor assíduo, devorador de romances, crônicas coloniais, 
relatos de viagem, estudos do Instituto Histórico e Geográfico brasileiro, dentre outros. Essa sede pela leitura pode ser percebida em suas obras de ficção e em sua correspondência, autobiografia, prefácios, pós-escritos e nas várias indicações de leitura em suas notas de rodapé dos seus romances. Esses elementos permitiram mapear um leitor que deixou registros de seus locais de leitura, das obras que leu e, principalmente, da apropriação das leituras que realizou. Em função disso, devemos perguntar onde leu José de Alencar?

Primeiramente, consideramos, além do onde ou os espaços de leitura, formas de viabilização ou de propagação da leitura. Nessa perspectiva, examinaremos, não apenas os espaços físicos dedicados à leitura, como Bibliotecas ou Gabinetes de leitura, mas, igualmente, jornais, obras literárias que se relacionam estreitamente com o ato de ler. $\mathrm{O}$ onde, pelo menos em Alencar, demonstra-se por essas vias de leitura. Para reconhecer os espaços de leitura de nosso leitor, devemos considerar onde se lia no Brasil no século XIX.

Inicialmente, no tocante aos locais de leitura, as livrarias (ou as lojas que vendiam livros dentre uma longa lista de outros produtos), escassas no Brasil decimonónico, segundo a maior parte das crônicas de época, precederam a imprensa, e diversas foram as casas portuguesas que solicitaram repetidamente autorização da Real Mesa Censória para enviarem livros para o Brasil desde os anos finais do século XVIII. Francisco Rolland, o mais famoso livreiro da cidade de Lisboa na época, por exemplo, fez tais solicitações em maio de 1796, fevereiro, maio e outubro de 1799, maio, outubro e novembro de 1800 , julho de 1801 , julho de 1802, abril de 1806, 1807, 1809 e assim por diante (CURTO, 2007, p. 311-15).
No século XIX, as livrarias brasileiras já desempenhavam um importante papel no cenário urbano e cultural:

Já nas décadas de 1820 e 1830, comerciantes franceses, portugueses e até alemães aproveitaram o gosto refinado de homens e mulheres pertencentes às camadas mais nobres e abastadas da corte imperial para vender autores e obras de mérito reconhecido na Europa. Houve também aqueles que trouxeram na bagagem uma bem vinda experiência no campo das impressões e publicações como foi o caso de Pierre Plancher [...] (EL FAR, 2006, p. 19).

Havia no Rio de Janeiro, desde a década de 1840, a livraria Garnier, responsável por um grande número de edições de autores nacionais - com particular destaque a José de Alencar que, uma vez tendo se estabelecido como escritor, passou a ser editado exclusivamente por esta casa editorial e livraria (Cf. HALLEWELL, 2005, p. 212). Garnier dividia espaço, dentre outros, com Eduardo Laemmert cuja Livraria Universal era outro foco de atividades literárias do Rio de Janeiro no século XIX.

Não tardou, entretanto, para que outros centros urbanos tentassem seguir a mesma receita [do Rio de Janeiro], na esperança de formarem uma clientela próspera e cativa. Em São Paulo, um ex-funcionário da Garnier, Anatole Louis Garraux, abriu, na Praça da Sé, nos anos 1860, a Casa Garraux. (EL FAR, 2006, p. 39).

Nas décadas seguintes, pelo menos as capitais de diversas províncias já alardeavam possuir locais de comércio de livros, como, por exemplo, a Pêndula Meridional, de Luis Coelho, fundada em Curitiba em 1776, seguida de perto pela Impressora Paranaense, criada 
nos anos 1880 para atender às necessidades econômicas criadas pela riqueza da erva-mate (DENIPOTI, 2008, p. 94-99).

Os clubes de leitura, que surgiram no Brasil já no início do século XIX, eram também espaços devotados ao mundo da palavra impressa, reunindo grupos de leitores que se organizavam de acordo com nacionalidades ou outras formas de afinidade. Exemplar desse tipo de lugar de leitura foi a British Subscripton Library (Cf. SCHAPOCHNIK, 2005), no Rio de Janeiro, seguida ou imitada por diversas outras instituições semelhantes Brasil adentro, como os gabinetes de leitura no Ceará, já na segunda metade daquele século (Cf. LIMA, 2011, p. 43). Havia também bibliotecas, como a do Museu Real (mais tarde, Museu Nacional), que, em 1847 "possuia uma biblioteca com três mil volumes", além de diversas outras instituições semelhantes, na Corte e nas províncias (DENIPOTI, 2007), que

[...] mostram o ritmo crescente de instalação de bibliotecas, gabinetes de leitura e várias outras instituições voltadas à leitura e aos empréstimos de livros, bem como sua diversificação espacial no país entre 1841-1860 e, sobretudo, entre 1861-1880 (DUTRA, 2010, p. 86).

Por outro lado, as bibliotecas particulares brasileiras de meados do século XIX se moldavam principalmente pelas trajetórias profissionais dos indivíduos que se dispunham a acumular livros - advogados, médicos e engenheiros sendo os mais facilmente identificáveis em inventários e catálogos de vendas de livros (Cf. FERREIRA, 1995, p. 1-90), em contraste com a proeminência de temas religiosos e filosóficos de bibliotecas do século anterior, tanto no Brasil quanto na Europa (Cf. ARAÚJO, 1999; VILLALTA, 1995).
Num segundo momento, consideramos as formas de divulgação de leitura. A imprensa periódica foi impulsionada pela vinda da família real para o Brasil em 1808, com a publicação da Gazeta do Rio de Janeiro (Cf SILVA, 2007) (de 1808 a 1822) e O Patriota (Cf KURY, 2007), a partir de 1813, a Idade d'Ouro do Brazil, (SILVA, 2005) publicada em Salvador a partir de 1811, em concorrência e concomitância com o Correio Braziliense ou Armazém Literário, de Hipólito José da Costa, publicado em Londres também entre 1808 e 1811. Ao longo do século XIX, esta imprensa cresceu exponencialmente, interiorizando a experiência editorial na forma de jornais, gazetas e almanaques mais ou menos efêmeros, escritos e impressos em capitais provinciais e cidades do interior de todas as províncias do país (Revista do Instituto Histórico e Geográfico Brasileiro. 1908), sem, contudo, deixar de parecer aos contemporâneos como um processo tímido, pois os parâmetros de comparação diziam sempre respeito a Paris e Londres, e, portanto, a populações com menores índices de analfabetismo. Simultaneamente, o universo editorial, movimentado por escritores como o próprio José de Alencar, e por editores como Garnier, e Phillipe Plancher, além de diversos outros que atuaram tanto na corte quanto nas províncias (Cf. HALLEWELL, 2005, p. 140305), ampliaram o universo de formação de um público leitor, o que permite, por sua vez, percebermos um crescimento em torno da cultura escrita, mesmo que populacionalmente restrita.

Neste espectro de possibilidades, como podemos encontrar o onde da leitura de José Alencar? Isto foi feito buscando os momentos em que o autor discursa sobre leitura em sua obra literária e em seus paratextos, ou seja, nos textos adicionais à obra - ou textos não ficcionais que fazem parte de obras literárias, como prefácios, posfácios, cartas ao leitor, pós-escritos, etc. 
Nessas narrativas - textos e paratextos - ele cita locais e formas de viabilização da leitura. Em outro artigo procurouse compreender a nota de rodapé como elemento constituinte da obra de José de Alencar, no sentido de que as construções discursivas contidas nas notas de rodapé fornecem indícios das leituras realizadas pelo autor, ao mesmo tempo que procuram legitimar, na historiografia que antecede o romance, as ideias sobre natureza, indígenas e nacionalidade que esse autor constrói em sua obra literária - especialmente as do chamado ciclo indigenista. As notas de rodapé, vistas em conjunção com outros elementos não ficcionais - os paratextos - da obra alencariana, permitem acessar a construção das ideias pertinentes à sua literatura. Ao mesmo tempo, permitem um acesso particular ao mundo da leitura no passado ao identificar práticas de leitura e as apropriações que Alencar fez de textos e ideias.

No que diz respeito aos locais da leitura alencariana, as notas e paratextos fornecem pistas que são reforçadas pelos textos, como, por exemplo, na autobiografia Como e porque sou romancista, na qual identificamos o registro de experiências familiares, políticas, intelectuais e, especialmente, experiências de leituras realizadas em vários momentos de sua trajetória: na infância - com as leituras em família para a mãe e para as tias -, na Faculdade de Direito em São Paulo - com as leituras de Balzac - e suas leituras em Olinda, no convento de São Bento. Esta é uma fonte privilegiada se observarmos que memórias, diários íntimos, autobiografias são fontes frequentemente utilizadas em pesquisas históricas em geral, com especial ênfase nos estudos referentes aos intelectuais. ${ }^{3}$

\footnotetext{
3 Exemplo disso é a pesquisa de Sergio Miceli e sua obra Intelectuais à brasileira, na qual relata como esses gêneros "[...] possibilitam apreender tanto as relações objetivas entre posições ocupadas pelas diversas categorias de intelectuais no interior do campo de produção cultural, e as determinações
}

Além disso, nota-se, uma preocupação acerca da análise desses escritos. Angela de Castro Gomes incluiu esses documentos - com correspondências e outras fontes privadas - no que define como escrita de si. Especificamente, a autobiografia alcançou seu apogeu no século XIX, acompanhando uma relação que se constituiu entre o indivíduo e seus documentos:

As sociedades modernas, nessa acepção,
são individualistas porque se consagram
tendoporbaseum contrato político-social
que reconhece todos os indivíduos como
livres e iguais, postulando sua autonomia
e abrindo campo para um novo tipo de
interesse sobre esse 'eu moderno'. Uma
idéia que confere à vida individual uma
importância até então desconhecida,
tornado-a matéria digna de ser narrada
como uma história que pode sobreviver
na memória de si e dos outros. É esse o
sentido da feliz observação de Levillain,
quando assinala que, se o ato de escrever
sobre vidas é muito antigo, a idéia de que
a vida é uma história é bem mais recente.
E é esse fundamento que está na base do
que se considera a escrita biográfica e
autobiográfica (GOMES, 2004, p. 10-11).

Queremos chamar a atenção para as últimas linhas acima citadas, que evidenciam que a vida de um determinado indivíduo é história. Essa questão ganha terreno no século XIX, não apenas, como afirma Gomes, pela constituição da ideia de indivíduo moderno. Podemos pensar, além disso, que a escrita de si tem seu apogeu nos oitocentos pela influência do crescimento e estabelecimento da História científica e nacional, construída simultaneamente à literatura que buscava, naquele momento, a constituição da nação. $\mathrm{Na}$ visão de história que se implantava, o papel do

sociais, escolares e culturais a que estão expostas, como as representações que os intelectuais mantêm com seu trabalho..." (MICELI, 2001, p. 85). 
indivíduo nessa constituição é fundamental, pois são as conquistas individuais que mapeiam a construção nacional, em geral por meio da busca de elementos heroicos na trajetória de artistas, políticos, militares, etc.

No caso de Alencar, o eu moderno abarca, igualmente, o escritor e o político conhecido pelo público. Dessa forma, a escrita de sua autobiografia considera diversos elementos. Primeiramente, concordamos com Gomes quando afirma que a prática da escrita de si aconteceria num espaço privado que "[...] de forma alguma elimina o público" (GOMES, 2004, p. 9). ou seja, pressupõe-se um leitor. Verdadeiramente, a autobiografia de Alencar tinha um leitor ou, melhor dizendo, um destinatário, pois foi escrita em forma de carta (provavelmente para Mario Alencar, que fez o prefácio da primeira edição) em 1873. Alencar já era um escritor renomado quando escreveu o texto, além disso, estava muito doente. A obra foi publicada após sua morte, em 1893, pela Tipografia Leuzinger.

O eu moderno, da citação de Angela de Castro Gomes acima, confere, dentre outras coisas, um sentido à vida individual. Esse significado se torna mais forte quando a escrita de si permite ao indivíduo sobreviver na memória do outro, como demonstra Constardo Calligaris:

[...]o que acontece quando ele começa a viver sua morte como uma tragédia, pois a comunidade para de ser grande depositária da vida, garantia de toda continuidade (CALLIGARIS, 1997. p. 5).

Dessa forma, o sujeito deve produzir um discurso de si. No caso de Alencar, tal narrativa foi escrita num período de doença, quatro anos antes de sua morte, esclarecendo, ainda que de forma concisa, a origem dessa fonte riquíssima de relatos acerca da cultura escrita do período no qual José de Alencar viveu. Todavia, a obra não pode ser tratada como um discurso verdadeiro e espontâneo, e sim como uma narrativa da escrita de si.

Tentamos buscar, nessa fonte, relatos individuais de leitura e descrições acerca da cultura escrita presentes em algumas fases da vida de Alencar. Em um primeiro momento, identificamos as passagens acerca do comércio livreiro, editores, bibliotecas, livrarias, gabinetes de leitura e bibliotecas privadas, com o objetivo de descobrir os locais da leitura alencariana. Para a comparação de algumas afirmações, cruzamos informações de sua autobiografia com a o diário de Joaquim Nabuco (1949) Minha Formação. Esse confronto de fontes foi necessário para identificarmos discursos comuns apresentados pelos autores de memórias, diários íntimos e autobiografias, fazendo os mesmos esclarecimentos sobre a obra de Joaquim Nabuco.

Primeiramente, Minha Formação foi escrita entre 1893-1899 - segundo o próprio Nabuco -, ou seja, posteriormente à autobiografia de Alencar. Em segundo lugar, a obra não apresenta o formato de correspondência encontrado em Como e porque sou romancista. Entretanto, os dois relatos apresentam estruturas narrativas semelhantes, na forma de uma 1) descrição do período estudantil, 2) de retomadas de antigos discursos e temas - esclarecimentos de polêmicas, desculpas, arrependimentos - e 3) da história familiar, através da qual se descreve a iniciação no universo da palavra impressa através da leitura. A obra de Nabuco poderá dar o contraponto necessário ao texto alencariano.

Acerca da história familiar, Joaquim Nabuco foi criado em um ambiente doméstico propício à leitura, como era a casa da família, em Paquetá, que lhe era particularmente interessante devido ao silêncio e isolamento que cercava a biblioteca. Para ele, a leitura 
era associada irremediavelmente à imagem de seu pai, que organizou a própria vida em torno dos livros:

Em 1860 meu pai mudou-se do Catete para a praia do Flamengo, onde residiu até a morte. A casa era uma dessas construções maciças ainda do bom tempo da edificação portuguesa do Rio de Janeiro, com proporções no interior de um trecho de palácio ou de convento. Ali, naqueles salões, e quartos que eram salas, ele estava à vontade, tinha o espaço e, com o mar em frente de suas Janelas, a variedade e o movimento exterior, precisos a um recluso dos livros (NABUCO, 1949, p. 70).

No caso de Alencar, em especial, algumas passagens narram os espaços de leitura. Observando suas experiências, identificamos espaços privados e públicos. O espaço privado pode ser percebido em duas citações, a primeira trata da leitura na infância e a segunda, na fase de seus estudos. Na infância, as leituras eram feitas na casa dos pais onde, além de ler cartas e jornais para sua mãe, lia, igualmente, a pequena biblioteca romântica:

Essa prenda que a educação deu-me para tomá-la pouco depois, valeu-me em casa o honroso cargo de ledor, com que me eu desvanecia, como nunca me sucedeu ao depois no magistério ou no parlamento. Era eu quem lia para minha boa mãe não somente as cartas e os jornais como os volumes de uma diminuta livraria romântica formada ao gosto do tempo [...] Nosso repertório romântico era pequeno; compunha-se de uma dúzia de obras entre as quais primavam a Amanda e Oscar, Saint-Clair das Ilhas, Celestina $e$ outras de que já não me recordo" (ALENCAR, 1990, p. 24- 29).

Nesse fragmento, o autor apresentase ledor oficial da casa de seu pai. A leitura relaciona-se com a infância, assumindo lugar de honra na família de Alencar. Além disso, o discurso pauta-se ainda em referências de leituras - jornais e romances - que fizeram parte da infância do escritor. $O$ honroso cargo de leitor na família aparece em outros momentos de sua autobiografia, narrando a prática da leitura em voz alta:

Não havendo visitas de cerimônia, sentava-se minha boa mãe e sua irmã D. Florinda como os amigos que apareciam, ao redor de uma mesa redonda de jacarandá, no centro da qual havia um candeeiro.

Minha mãe e minha tia se ocupavam com trabalhos de costuras, e as amigas pra não ficarem ociosas as ajudavam. Dados os primeiros momentos a conversação, passava-se a leitura e era eu chamado ao lugar de honra.

Muitas vezes, confesso, essa hora me arrancava bem a contragosto de um sono começado ou de um folguedo querido; já naquela idade a reputação é um fardo e bem pesado.

Lia-se até a hora do chá, e tópicos havia tão interessantes que eu era obrigado à repetição. Compensavam esse excesso, as pausas para dar lugar às expansões do auditório, o qual desfaziase em recriminações contra algum mau personagem, ou acompanhava de seus votos e simpatias o herói perseguido.

Uma noite, daquelas em que eu estava mais possuído do livro, lia com expressão uma das páginas mais comoventes de nossa biblioteca. As senhoras, de cabeça baixa, levavam o lenço ao rosto, e poucos momentos depois não puderam conter os soluços que rompiam-lhes o seio (ALENCAR, 1990, p. 8-27).

A prática da leitura em voz alta nesse fragmento nos esclarece como a leitura assumia configurações diferenciadas, desenvolvendose, portanto, em várias direções (DARNTON, 1992, p. 212) e, nesse caso, uma leitura que tinha como objetivo ser ouvida. A leitura em voz alta é vista com atenção pelos historiadores 
que se dedicam ao estudo desta prática cultural. Chartier (2004b, p. 11) lembra-nos que compreender a leitura significa

[...]não considerar que o acesso ao texto escrito é sempre e em toda parte uma leitura individual, silenciosa, solitária, que supõe necessariamente a alfabetização.

Igualmente, Darnton (1992, p. 216) recorda como na França oitocentista grupos de artesãos - fabricantes de charutos e alfaiates amenizavam a jornada de trabalho ouvindo um leitor. A cena descrita por Darnton assemelhase com o fragmento autobiográfico de Alencar citado acima: ouve-se a leitura ou para amenizar ou para entreter. Ambos - Darnton e Alencar - colocam-nos outra questão: que livros deveriam ser ouvidos/lidos?

No caso de Alencar - e especificamente nesse relato - identificamos o material de leitura: cartas, jornais (ambos lidos para a mãe) e títulos de uma pequena biblioteca romântica que, lidos como expressão, comoviam as senhoras presentes, o que pode nos demonstrar como a leitura em voz alta não deve ser compreendida como um ato privado pois "[...] a escolha do material de leitura deve ser socialmente aceitável tanto para o leitor como para o público" (MANGUEL, 1997. p. 145).

Desta forma, o documento de Alencar nos esclarece como a leitura em voz alta, ao participar das reuniões sociais na casa de seus pais, gerou significados ímpares e diferenciados para ele. Entretanto, essa prática foi, aos poucos, abandonada ou esquecida em sua autobiografia, e foi substituída - ainda falando sobre o espaço privado - pela leitura silenciosa e reclusa.

Identificamos, igualmente, o espaço privado de leitura na juventude de nosso leitor: a formação de bibliotecas comuns para as quais cada estudante levava uma modesta provisão, montando um acervo literário que incluía obras de Honoré Balzac, François Fenelon, Alexandre Dumas, Alfredo Vigny, François-René de Chateaubriand, Victor Hugo, George Gordon Byron, entre outros. $\mathrm{O}$ uso da biblioteca comum possibilitou a formação de um círculo de leitura alternativo, especialmente entre os estudantes que viviam em repúblicas e comunhões acadêmicas de São Paulo, Rio de Janeiro e Olinda. Tal prática pode ser percebida em passagens da autobiografia de Alencar. Nesses momentos, o autor discorre acerca de suas leituras e das obras emprestadas que estavam à disposição dos estudantes paulistas:

Uma das livrarias, a que maior cabedal trazia a nossa comum biblioteca, era a de Francisco Otaviano, que herdou do pai uma escolhida coleção das obras dos melhores escritores da literatura moderna, a qual o jovem poeta não se descuidava de enriquecer com as últimas publicações.

Meu companheiro de casa era dos amigos de Otaviano, e estava no direito de usufruir sua opulência literária. Foi assim que um dia vi pela primeira vez o volume das obras completas de Balzac, nessa edição em folha que os tipógrafos da Bélgica vulgarizam por preço módico. As horas que meu companheiro permanecia fora, passava-as eu com o volume na mão, a reler os títulos de cada romance da coleção, hesitando na escolha daquele por onde havia de começar (ALENCAR, 1990, p. 39).

Os espaços públicos de leitura se contrapõem à leitura privada, doméstica e estudantil, devotada à literatura, que incitava emocionalmente tanto Alencar, como Nabuco $(1949$, p. 27) que se sentiu, diante da biblioteca particular de Ernest Renan em Paris, 
[...] como Luís II da Baviera na escuridão do camarote real, no teatro vazio, vendo representar os Niebelungen em uma cena iluminada para ele só.

Essa leitura de espaço público pode ser encontrada na autobiografia de Alencar, como, por exemplo, a narrativa sobre a filiação a um gabinete de leitura:

Com as minhas bem parcas sobras, tomei uma assinatura em um gabinete de leitura que então havia à Rua da Alfândega, e que possuía copiosa coleção das melhores novelas e romances até então saídos dos prelos franceses e belgas (ALENCAR, 1990, p. 50).

Segundo Germana Sales (2003, p. 35), no processo de expansão da leitura no Brasil, os gabinetes de leitura tiveram um papel fundamental, primeiramente porque eram espaços de leitura e, segundo, porque introduziram uma nova prática: a locação de livros. Como visto acima, além dos gabinetes, as bibliotecas incluem-se nesses espaços, entretanto, o acesso, embora gratuito, era limitado a um público circunscrito a uma elite de intelectuais e eruditos (Cf. SALES, 2003, p. 9-38). Nesse caso, os espaços públicos na obra de Alencar eram locais destinados à elite, ou seja, aos intelectuais do período que aderiram aos gabinetes de leitura.

Os relatos de Alencar apontam, igualmente, semelhanças entre os hábitos de leitura desenvolvidos na Europa e os inseridos na sociedade brasileira do período oitocentista. Podemos afirmar que o perfil do leitor moderno encontra-se igualmente no Brasil. Os historiadores da leitura indicam uma mudança profunda nas práticas de leitura, associada às mudanças técnicas e intelectuais que acompanharam a Revolução Industrial, por um lado, e a ascensão do Iluminismo, em suas diversas interpretações, por outro. A partir do século XVIII, a leitura era intensiva, ou seja, liam-se alguns poucos livros - geralmente religiosos - repetidas vezes. A partir de então, uma leitura extensiva, mais variada, passou a ser praticada, com os leitores tendo acesso a diversos livros, buscando sempre a mais recente novidade, que será lida uma vez e descartada logo após a leitura em favor de um texto mais novo ou desconhecido. No caso de Alencar, podemos identificálo como leitor moderno. Prova disso são as citações de diversos autores descritores da geografia e do indígena brasileiro nos séculos anteriores, em suas notas de rodapé, que referenciam as construções indigenistas que marcaram parte da obra alencariana. Também evidenciam isso os vários romances lidos e citados em sua autobiografia ou nas Cartas sobre a confederação dos Tamoios e a leitura de suas personagens, especialmente as participantes dos romances urbanos (Cf. ALENCAR, 1856).

Por exemplo, em Lucíola, de 1862, encontramos o leitor moderno na personagem Paulo, que lia contos de Bernardin de SaintPierre, Chateaubriand, a Bíblia, dentre outros, para sua amiga e amante Lúcia:

[...] foi à estante escolher um livro, e sentou-se na esteira para ouvir-me ler. O livro que ela trouxe era esse gracioso conto de Bernardin de Saint-Pierre [...] (ALENCAR, [19-], p. 155).

Nas Cartas sobre a confederação dos Tamoios, Alencar demonstra, claramente, sua leitura extensiva nas várias citações de autores como Victor Hugo, Virgílio e Homero, dando assim o caráter público de suas leituras, da mesma forma que Joaquim Nabuco o faz, ao afirmar que no 
[...] ano de 1866 foi para mim o ano da Revolução francesa: Lamartine, Thiers, Mignet, Louis Blanc, Quinet, Mirabeau, Vergniaud e os Girondinos [...] (AUTOR, ANO, P.?)

e que, no

[...]livro de minhas leituras de 1869, quarto ano da Academia, encontro no índice, com muita Escravidão e muito Cristianismo, muita Eloqüência inglesa, muito Fox e Pitt (NABUCO, 1949, p. 4).

Encontramos, nessas duas narrativas, a valorização da leitura como também a necessidade de se propagar as obras lidas, afirmando suas influências.

A outra via pública de leitura em Alencar encontra-se no comércio livreiro e na imprensa tipográfica nacional que, em sua autobiografia, abarca os anos de 1846 a 1848, passados na cidade de São Paulo. Alencar classificou o comércio livreiro como precário, em consonância com a historiografia acerca do tema (HALLEWELL, 2005, p. 297):

Naquele tempo o comércio dos livros era, como ainda hoje, artigo de luxo; todavia, apesar de mais baratas, as obras literárias tinham menor circulação. Provinha isso da escassez das comunicações com a Europa, e da maior raridade de livrarias e gabinetes de leitura.

Cada estudante, porém, levava consigo a modesta provisão que juntara durante as férias, e cujo uso entrava logo para a comunhão escolástica (ALENCAR, 1990, p. 38).

Cabe observar que o comércio de livros no Brasil sofrera recentes alterações que o tornaram mais dinâmico com relação ao início do período independente do país. A disseminação generalizada, por exemplo, do uso de transportes navais a vapor, a partir do final da década de 1830, fez reduzir o tempo de viagem entre os diversos portos nacionais e, duas décadas depois, entre o Brasil e a Europa. Essa mudança fez com que o comércio (e o comércio de livros em particular), antes com alto índice de autonomia, com ligações diretas entre as capitais provinciais e os fornecedores europeus, passasse a ser centralizado na Corte, e a partir dali, redistribuído pelos vapores de cabotagem. Em certo grau, isso se aplica também às práticas editoriais, enormemente dependentes do comércio internacional para o fornecimento de suprimentos - papel, tinta, tipos, etc. (Cf. HALLEWELL, 2005, p. 7-126).

Alencar dedicou o último capítulo de sua autobiografia à situação da imprensa tipográfica brasileira e ao trabalho do escritor. Ao analisar esse fragmento da obra, temos a impressão de que a finalização de Como e porque sou romancista se apresenta como um desabafo. Entre as descrições dos novos acontecimentos no campo literário e jornalístico e as respostas às inúmeras críticas sofridas no decorrer de sua carreira literária, Alencar discorreu acerca de suas obras, seus leitores e, principalmente, acerca da imprensa tipográfica e sua precariedade. Ressalta como editou Lucíola (1862) e Iracema (1865) por conta própria, e em relação a As Minas de Prata, afirmou:

A composição dos cinco últimos volumes d'As Minas de Prata ocupoume três meses entre 1864 e 1865; porém a demorada impressão estorvou-me um ano, que tanto durou. Ninguém sabe da má influência que tem exercido na minha carreira de escritor, o atraso de nossa arte tipográfica, que um constante caiporismo torna em péssima para mim. (ALENCAR, 1990, p. 9-68).

Essa questão, junto ao surgimento e ao crescimento tardio do comércio livreiro e da 
indústria tipográfica, pode esclarecer como a literatura no Brasil oitocentista era um péssimo negócio para o escritor:

Todavia ainda para o que teve a fortuna de obter um editor, o bom livro é no Brasil e por muito tempo será para seu autor, um desastre financeiro. $\mathrm{O}$ cabedal de inteligência e trabalho que nele se emprega, daria em qualquer outra aplicação, lucro cêntuplo. (ALENCAR, 1990, p. 68-70).

Certamente, tais relatos apontam para um círculo livreiro que, embora acanhado e precário, segundo a própria visão de Alencar, envolvia instituições, associações, editores, livreiros, leitores dentre outros - ou seja, o circuito de comunicação da leitura teorizado por Robert Darnton (2002, p. 10-26) - e, consequentemente, o lugar público da leitura. Os desdobramentos do comércio de livros, e da produção editorial, capitaneado por livreiros que se tornaram centros gravitacionais do mercado cultural do século XIX, transformaram as livrarias em verdadeiros salões, nos quais os literatos tornavam públicas suas formas de leitura - suas aversões e adesões canônicas, por exemplo. (Cf. DUTRA, 2010, p. 70-71).

O discurso acerca da leitura em Alencar não se pauta, porém, apenas nas vias privada e pública ou em seus paratextos prefácios, pós-escritos, autobiografia e notas de rodapé. $\mathrm{Na}$ realidade, a questão da leitura apresenta-se em várias passagens da sua obra completa como, por exemplo, nas que tratam de suas leitoras ficcionais.

Em Diva, Emília "tinha na mão um livro aberto e lia com atenção", diferentemente de Lucíola (1862) na qual Alencar fala sobre as leituras rápidas e sem método de Lúcia, como, igualmente, algumas obras que essa leitora fictícia teria devorado diariamente ou escutado de seu amante e ledor Paulo:

Lúcia conservava de tempos passados o hábito da leitura e do estudo; raro o dia em que não se distraía uma hora pelo menos com o primeiro livro que lhe caía nas mãos. Dessas leituras rápidas e sem método provinha a profusão de noções variadas e imperfeitas que ela adquiria e se revelavam na sua conversação (ALENCAR, [19-], p. 91).

A passagem da leitura de Lúcia aponta, ainda, dois elementos que, constantemente, aparecem nas descrições de leituras em José de Alencar: o método e a concentração. Nos discursos identificados acerca da leitura, Alencar insiste em ressaltar a importância do método e da concentração. Lúcia, que não apresentava esses elementos, é descrita pelo autor como uma leitora de noções variadas, ou seja, as leituras rápidas da amante de Paulo são criticadas pelo narrador e nos dão pistas de como deveria ser, para Alencar, o leitor e a leitura ideal.

Em conclusão, a obra de José de Alencar, em sua totalidade - romances, autobiografia, e paratextos - nos permite, em primeiro lugar, apreender algumas das apropriações de leituras feitas por ele no seu papel de leitor. Como ele leu é fundamental para a compreensão do que ele escreveu. O como da leitura é dado pelo conjunto de práticas, incluindo aí os locais de leitura. Em segundo lugar, é possível buscar pistas sobre a leitura no passado perseguindo essas práticas de leitura, seja no discurso autobiográfico, sejam nas caracterizações ficcionais de seus romances.

À pergunta onde leu Alencar, ou quais foram os locais da leitura desse escritor - e muito provavelmente de diversos outros seus contemporâneos brasileiros circulando pelos ambientes urbanos do século XIX - as respostas retiradas 
de sua autobiografia inserem-no em práticas culturais interrompidas, ao longo dos séculos seguintes, por novas formas de sociabilidade privada e pública. Leituras em família, horas de leitura em literatura que surgia como novidade, leitura recomendada através das personagens fictícias, são formas de leitura. Práticas culturais que permitem compreender melhor o indivíduo, seu entorno social e as visões de mundo daí derivadas, e que, como todo o conhecimento histórico, demandam mais debate e investigação por parte dos historiadores.

O que este artigo buscou explorar foram os locais de leitura no Brasil de fins do século
XIX, a partir das práticas culturas descritas nos textos ficcionais e paratextos de José de Alencar, auxiliado por textos semelhantes escritos por Joaquim Nabuco. A ampliação deste universo documental deve, porém, confirmar que as práticas culturais descritas ali predominaram e definiram as formas de sociabilidade em torno da palavra escrita e se suas formas de leitura. Locais de leitura estão relacionados diretamente às tensões e clivagens sociais definidas pelo conflito representacional em torno da leitura, e este artigo buscou ampliar a compreensão desses processos, incitando novas pesquisas acerca do tema.

\section{REFERÊNCIAS}

ALENCAR, J. Lucíola. São Paulo: Edições Melhoramentos, [19-].

ALENCAR, J. Cartas sobre a confederação dos Tamoios. Rio de Janeiro: Empreza Typographica do Diario, 1856.

ALENCAR, J. Como e porque sou romancista. Campinas: Pontes, 1990.

ARAÚJO, A. C. Livros de uma vida; critérios e modalidades de constituição de uma livraria particular no século XVIII. Revista de História das Ideas, 20, 149-185, 1999.

BURKE, P. Variedades de história cultural. Rio de Janeiro: Civilização Brasileira, 2000.

. O que é história cultural? Rio de Janeiro: Zahar, 2005.

CALLIGARIS, C. Verdades de autobiografias e diários íntimos. Estudos Históricos: Indivíduo, biografia, história. Rio de Janeiro: FGV, 1997. n 19.

CANNADINE, D. British history: past, present and future. Past and Present, London, n. 116, Aug. 1987.p. 170.

CARDOSO JR.; REBELLO, H. Tramas de clio: convivência entre filosofia e história. Curitiba: Aos Quatro Ventos, 2001.

CHARTIER, R. Forms and meanings: texts, performances and audiences, from codex to computer. Pennsylvania: University of Pennsylvania Press, 1995. 
. Languages, books and reading, from the printed word to the digital text. Critical Inquiry I, Autum 2004a, vol. 31, issue 01, p. 133-152.

. Leituras e leitores na França do Antigo Regime. São Paulo: UNESP, 2004b. p. 11.

CURTO, D. Ramada, et. al. As gentes do livro. Lisboa, século XVIII. Lisboa: Biblioteca Nacional, 2007.

DARNTON, R. O grande massacre de gatos e outros episódios da história cultural francesa. Rio de Janeiro: Graal, 1986.

. História da leitura. In: BURKE, P., (Org.). A escrita da história: novas perspectivas. São Paulo: Editora da Universidade Estadual Paulista, 1992.

DARNTON, R. What is the history of the books. In: FINKELSTEIN, D.; McCLEERY, eds. Book history reader. New York: Routledge, 2002. p. 10-26.

DENIPOTI, C. Decência imperial, silêncio republicano; normas e gestualidades da leitura em regimentos e estatutos de bibliotecas (1821-1918). Varia História, Belo Horizonte, v. 23, n. 38: p. 597-614, jul./dez. 2007.

Cláudio. As Livrarias de Curitiba no início do século XX. In: TEIXEIRA, Valéria Marques. Histórias de Curitiba. Curitiba: Fundação Cultural de Curitiba, 2008.

A gentil loucura; as representações da bibliomania nos séculos XVIII e XIX. In: GRUNER, Clóvis \& DENIPOTI, Cláudio, orgs. Nas tramas da ficção; história, literatura e leitura. São Paulo: Ateliê, 2009, p. 177-197.

DUTRA, E. F. Leitores de Além-mar; a editora Garnier e sua aventura editorial no Brasil. In: BRAGANÇA, Anibal \& ABREU, Márcia, orgs. Impresso no Brasil; dois séculos de livros brasileiros. São Paulo: Unesp, 2010.

EL FAR, A. O livro e a leitura no Brasil. Rio de Janeiro: Jorge Zahar., 2006.

FERREIRA, T. M. T. Bessone da Cruz. Leitores do Rio de Janeiro; Bibliotecas como jardins das delícias. Acervo, v. 8, n. 01-02, Jan-dez 1995, p. 83-104.

FINKELSTEIN, D.; McCLEERY.. Book history reader. New York: Routledge, 2002.

GOMES, A. C. (Org.). Escrita de si, escrita da história. Rio de Janeiro: Editora FGV, 2004.

HALLEWELL, L. O livro no Brasil: sua história. São Paulo: Universidade de São Paulo, 2005, 2. ed. revista e ampliada. 
KURY, Lorelai. Iluminismo e Império no Brasil. O Patriota (1813-1814). Rio de Janeiro: Fiocruz, 2007.

LIMA, L. F. Entre caminhos e lugares do livro; gabinetes de leitura na região norte do Ceará (18771919). Fortaleza: UFCE. Mestrado em História, 2011.

MANGUEL, A. Uma história da leitura. São Paulo: Companhia das Letras, 1997.

MICELI S. Intelectuais à brasileira. São Paulo: Companhia das Letras, 2001.

NABUCO, J. Minha Formação. São Paulo: Instituto Progresso Editorial S.A., 1949.

SCHAPOCHNIK, N. The Rio de Janeiro British Subscription Library. Caminhos dos Romance no Brasil séculos XVIII e XIX, Campinas, p. 01-24, 2005. Disponível em: <http:// www.caminhosdoromance.iel.unicamp.br/estudos/ensaios/bibliotecadesaparecida.pdf $>$ Acesso em: 15 abr. 2013.

Revista do Instituto Histórico e Geográfico Brasileiro. Rio de Janeiro: Imprensa Nacional, 1908.

SALES, G. M. A. S. Palavra e sedução: uma leitura dos prefácios oitocentistas (1820-1881). Campinas, 2003. Tese (Doutorado) - Universidade de Campinas, Campinas, 2003..

SILVA, M. B. N. A primeira gazeta da Bahia Idade d'Ouro do Brazil. Salvador: UFBA, 2005. . A Gazeta do Rio de Janeiro (1808-1822): cultura e sociedade. Rio de Janeiro: UERJ, 2007.

VEYNE, P. Como se escreve a história. Lisboa: Edições 70, 1983.

VILLALTA, L. C.. Os clérigos e os livros nas Minas Gerais da segunda metade do século XVIII. Acervo, v. 8, n. 01-02, Jan-dez 1995, p.19-52. 